UPAYA MENINGKATKAN RESEARCH SKILL SISWA MELALUI

CITIZEN SCIENCE PROJECT PADA PEMBELAJARAN BIOLOGI SMA

SKRIPSI

diajukan untuk memenuhi salah satu syarat untuk memperoleh gelar

Sarjana Pendidikan Program Studi Pendidikan Biologi

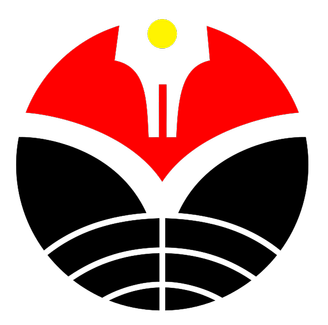

Oleh :

Della Frisca Damayanti

NIM 1700069

PROGRAM STUDI PENDIDIKAN BIOLOGI

DEPARTEMEN PENDIDIKAN BIOLOGI

FAKULTAS PENDIDIKAN MATEMATIKA DAN ILMU PENGETAHUAN ALAM

UNIVERSITAS PENDIDIKAN INDONESIA

BANDUNG

2021

Della Frisca Damayanti, 2021

UPAYA MENINGKATKAN RESEARCH SKILL SISWA MELALUI CITIZEN SCIENCE PROJECT PADA

PEMBELAJARAN BIOLOGI SMA

Universitas Pendidikan Indonesia $\mid$ respository.upi.edu perpustakaan.upi.edu 
UPAYA MENINGKATKAN RESEARCH SKILL SISWA MELALUI CITIZEN SCIENCE PROJECT PADA PEMBELAJARAN BIOLOGI SMA

oleh

Della Frisca Damayanti

1700069

Sebuah skripsi yang disusun untuk memenuhi salah satu syarat memperoleh gelar Sarjana Pendidikan pada Fakultas Pendidikan Matematika dan Ilmu Pengetahuan Alam

\author{
CDella Frisca Damayanti \\ Universitas Pendidikan Indonesia
}

Agustus 2021

Hak Cipta dilindungi undang-undang.

Skripsi ini tidak boleh diperbanyak seluruhya atau sebagian, dengan dicetak ulang, difoto kopi, atau cara lainnya tanpa ijin dari penulis. 
LEMBAR PENGESAHAN

\section{DELLA FRISCA DAMAYANTI \\ UPAYA MENINGKATKAN RESEARCH SKILL SISWA MELALUI CITIZEN SCIENCE PROJECT PADA PEMBELAJARAN BIOLOGI SMA}

Disetujui dan disahkan oleh pembimbing:

Pembimbing I

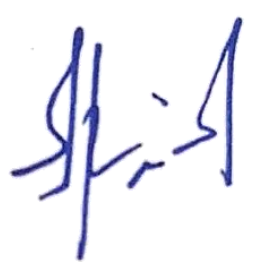

Dr. Rini Solihat, M.Si.

NIP. 197902132001122001

Pembimbing II

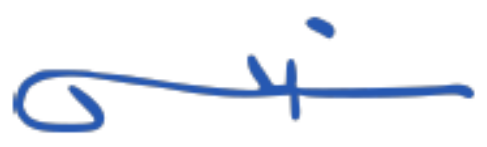

Prof. Topik Hidayat, M.Si., Ph.D.

NIP. 197004101997021001

Mengetahui,

Ketua Program Studi Pendidikan Biologi

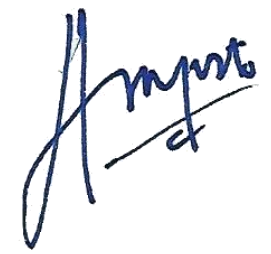

Dr. Amprasto, M.Si.

NIP. 196607161991011001 


\title{
ABSTRAK \\ UPAYA MENINGKATKAN RESEARCH SKILL SISWA MELALUI CITIZEN SCIENCE PROJECT PADA PEMBELAJARAN BIOLOGI SMA
}

\author{
Della Frisca Damayanti
}

Citizen science project merupakan inovasi dalam kegiatan pembelajaran berbasis masalah yang merangsang siswa untuk tertarik melakukan penelitian ilmiah. Keterampilan siswa dalam suatu penelitian ilmiah menjadi tuntutan yang harus dipenuhi oleh siswa. Maka dari itu, penelitian ini dilakukan untuk menganalisis peningkatan Research Skill siswa melalui Citizen Science Project pada Pembelajaran Biologi SMA. Metode yang digunakan pada penelitian ini adalah Pre-Experiment dengan desain single-group pre-test \& post-test dan subjek penelitian siswa kelas X MIPA berjumlah 32 siswa. Instrumen yang digunakan adalah lembar tes research skill siswa, rubrik penilaian research skill dari lembar kerja siswa, lembar observasi, pedoman wawancara, dan rubrik pencapaian research skill siswa. Research skill siswa sebelum menunjukan rata-rata 63,4 dengan standar deviasi $\pm 13,3$ dan research skill siswa setelah menunjukan rata-rata 83,8 dengan standar deviasi $\pm 9,42$. Adapun proporsi kategori $\mathrm{N}$-Gain research skill siswa bervariasi, 6,2\% untuk kategori rendah, 71,9\% untuk kategori sedang, dan 21,9\% untuk kategori tinggi. Peningkatan indikator research skill tertinggi yaitu questioning, sedangkan terendah adalah planning. Adapun pada saat pelaksanaan citizen science project diketahui bahwa research skill saat merancang menunjukan hasil yang cukup baik. Adapula data hasil monitoring keterlaksanaan proyek menunjukkan bahwa secara umum siswa sudah mampu melaksanakan citizen science project hingga selesai. Dapat disimpulkan bahwa citizen science project berkontribusi positif terhadap research skill siswa pada materi upaya pelestarian keanekaragaman tumbuhan dan pemanfaatannya dalam kehidupan.

Kata kunci: Research Skill, Citizen Science Project, Pembelajaran Biologi 


\title{
ABSTRACT \\ EFFORTS TO IMPROVE STUDENT'S RESEARCH SKILL THROUGH CITIZEN SCIENCE PROJECT IN BIOLOGY LEARNING FOR HIGH SCHOOL
}

\author{
Della Frisca Damayanti
}

Citizen science project is an innovation in problem-based learning activities that stimulate students to be interested in doing scientific research. Students' skill in scientific research are demands that must be met by students. Therfore, this study was conducted to analyze the improvement of students' research skills through citizen science project in Biology learning for high school. The method used in this research is Pre-Experiment with a singlegroup pre-test \& post-test design and the research subject were 32 students of class $\mathrm{X}$ MIPA. The instruments that used were student research skills test sheets, rubrics for assessing research skills from student worksheets, observation sheets, interviews, and rubrics for assessing student research skills. The research skills of the students before showed an average of 63.4 with a standard deviation of \pm 13.3 and the research skills of the students after showed an average of 83.8 with a standard deviation of \pm 9.42 . The proportion of students' N-Gain research skill category varies, $6.2 \%$ for the low category, $71.9 \%$ for the medium category, and $21.9 \%$ for the high category. The highest increase in the research skill indicator is questioning, while the lowest is planning. Meanwhile, during the implementation of the citizen science project, it was known that the research skill when designing showed good results. There are also data from the monitoring results of project implementation showing that in general they have been able to carry out citizen science projects to completion. It can be said that the citizen science project contributes positively to students' research skill on the subject of preserving plant diversity and its use in life.

Keyword: Research Skill, Citizen Science Project, Biology Learning 
LEMBAR PENGESAHAN _................................................................ i

LEMBAR PERNYATAAN ...................................................................... ii

UCAPAN TERIMAKASIH........................................................................ iii

ABSTRAK ….............................................................................................. $\quad \mathbf{v}$

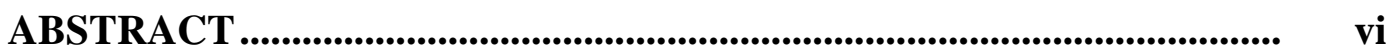

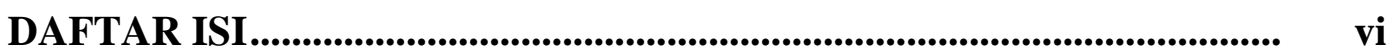

DAFTAR TABEL _.......................................................................................... $x$

DAFTAR GAMBAR .........................................................................

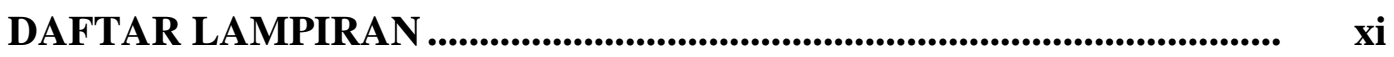

\section{BAB I PENDAHULUAN}

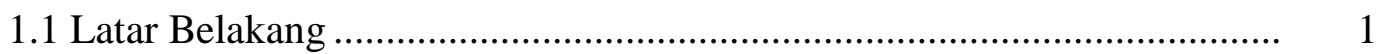

1.2 Rumusan Masalah .................................................................................. 4

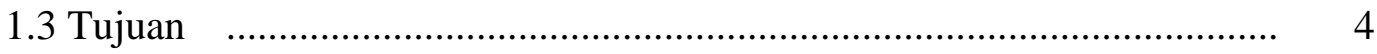

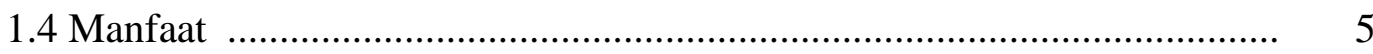

1.5 Batasan Masalah............................................................................... 5

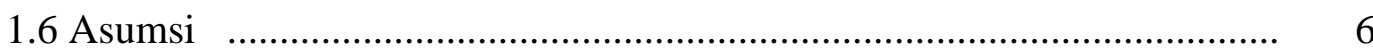

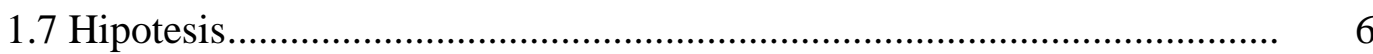

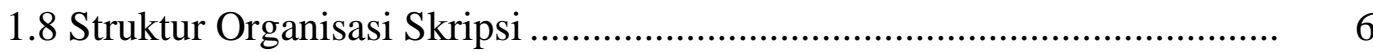

BAB II RESEARCH SKILL, CITIZEN SCIENCE PROJECT, DAN MATERI KEANEKARAGAMAN HAYATI

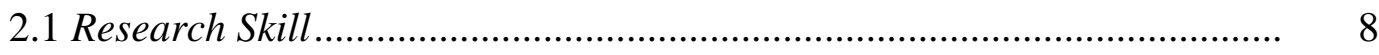

2.2 Citizen Science Project ........................................................................ 12

2.3 Karakteristik Materi Keanekaragaman Hayati........................................ 16

2.4 Deskripsi Materi Keanekaragaman Hayati .............................................. 19

\section{BAB III METODE PENELITIAN}

3.1 Definisi Operasional............................................................................ 22

3.2 Metode dan Desain Penelitian............................................................... 22 
3.3 Populasi dan Sampel ................................................................... 23

3.4 Instrumen Penelitian........................................................................... 23

3.5 Proses Pengembangan Instrumen........................................................... $\quad 30$

3.6 Teknik Pengumpulan Data...................................................................... 33

3.7 Prosedur Penelitian............................................................................... 35

3.8 Analisis Data .................................................................................. 40

3.9 Alur Penelitian ................................................................................ 43

\section{BAB IV TEMUAN DAN PEMBAHASAN}

4.1 Research Skill Siswa Sebelum Mengikuti Pembelajaran Biologi Menggunakan

Citizen Science Project ........................................................................ 44

4.2 Research Skill Siswa Setelah Mengikuti Pembelajaran Biologi Menggunakan

Citizen Science Project ...................................................................... 47

4.3 Proporsi Kategori N-Gain Research Skill Siswa Setelah Mengikuti Pembelajaran Biologi Menggunakan Citizen Science Project................... 50

4.4 Research Skill Siswa Saat Merancang dan Melaksanakan Penelitian pada Materi Upaya Pelestarian Keanekaragaman Tumbuhan dan Pemanfaatannya dalam Kehidupan ...................................................................................... 54

\section{BAB V SIMPULAN, IMPLIKASI, DAN REKOMENDASI}

5.1 Simpulan ..................................................................................... 74

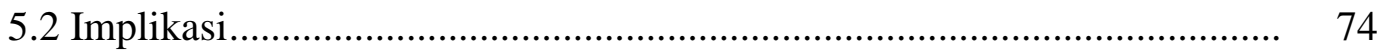

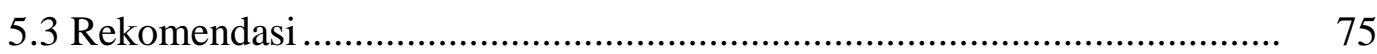

DAFTAR PUSTAKA ............................................................................................ 76

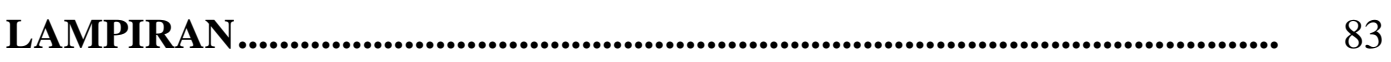

RIWAYAT HIDUP ............................................................................................. 151 


\section{DAFTAR PUSTAKA}

Afrianto, W. F. \& Najah, S. K. (2017). Peran Citizen Science dalam Upaya Konservasi Biodiversitas. EKOKONSERVASI, 6(1).

Anugrahana, A. (2020). Hambatan, Solusi, dan Harapan: Pembelajaran Daring Selama Masa Pandemi Covid-19 Oleh Guru Sekolah Dasar. Scholaria: Jurnal Pendidikan dan Kebudayaan, 10(3).

Anwar, A. (2019). Kriteria Topik dan Petunjuk Penulisan Artikel JEK. [Online].

Diakses dari: https://media.neliti.com/media/publications/83803-ID-backmetter.pdf (4 Agustus 2021).

Aprilia, L., Sutaryadi, \& Susilowati, T. (2013). Penanganan Perbedaan Individual Dalam Proses Pembelajaran Stenografi. Jurnal Pendidikan Administrasi Perkantoran, 2(2).

Arikunto, S. (2011). Dasar-dasar Evaluasi Pendidikan. Jakarta: Bumi Aksara.

Badan Pengembangan dan Pemberdayaan SDM Kesehatan. (2017). Pedoman Monitoring dan Evaluasi Pembelajaran. [Online]. Diakses dari: http://bppsdmk.kemkes.go.id/pusdiksdmk/wpcontent/uploads/2018/01/PEDO MAN-MONEV_-2017-1.pdf (21 Juli 2021).

Bonney, R., Ballard, H., Jordan, R., McCallie, E., Phillips, T., Shirk, J., \& Wilderman, C. (2009). Public Participation in Scientific Research: Defining the Field and Assessing Its Potential for Informal Science Education. A CAISE Inquiry Group Report. Online Submission, July.

Budimansyah, D. (2009). Inovasi Pembelajaran Project Citizen. Bandung: Program Studi PKN SPS UPI.

California Academyof Sciences. (2015). Citizen Science Toolkit: Teaching Science Through Citizen Science. Pearson Foundation.

Chairani, Shanty. (2016). Peningkatan Minat Belajar Peserta Didik melalui Metode Praktikum pada Materi Metabolisme di SMAN 3 Tanggerang Selatan. Prosiding Temu Ilmiah Nasional Gutru (TING). Universitas Terbuka Convention Center.

Charitas, R., \& Prahmana, I. (2018). The Role of Research-Based Learning to Enhance Students' Research and The Role of Research-Based Learning to 
Enhance Students ' Research and Academic Writing Skills. August 2017. https://doi.org/10.11591/edulearn.v11i3.5871

Cohn, J. P. (2008). Citizen science: Can volunteers do real research? BioScience, 58(3), 192-197. https://doi.org/10.1641/B580303

Creswell, J. W. (2017). Research design: pendekatan kualitatif, kuantitatif, dan mixed. Yogyakarta: PT. Pustaka Belajar.

Dixon, W. M., Agarwal, S., Young, B., Jones, D. \& Sutton, A. (2004). Integrative 128 Approaches to Qualitative and Quantitative Evidance. London: Health Development Agency.

Ferran-Ferrer, N. (2015). Volunteer participation in citizen science projects. Profesional de La Informacion, 24(6), 827-837. https://doi.org/10.3145/epi.2015.nov.15

Gultom, S.T., Riandi, Solihat, R., Siahaan, P., \& Sinaga, R. (2021). "Implementation of ESD with a Problem Based Learning Model Using Blended E-Learning to Analyze the Level of Environmental Awareness in Science Learning in Junior High Schools". Dalam Arka Yanitama, Andhina Putri H., \& Trida Ridho F. (Penyunting), PROSIDING SEMINAR NASIONAL IPA Universitas Negeri Semarang. (hlm. 124-128). Semarang: LPPM Universitas Negeri Semarang.

Hake, R, R. (1999). Analyzing Change/Gain Scores. Woodland Hills: Dept. of Physics, Indiana University.

Haklay, M., (2013). Citizen Science and Volunteered Geographic Information overview and typology of participation in Sui, D.Z., Elwood, S. and M.F. Goodchild (eds.), 2013. Crowdsourcing Geographic Knowledge: Volunteered Geographic Information (VGI) in Theory and Practice . Berlin: Springer. pp 105-122 DOI: 10.1007/978-94-007-4587-2_7

Herman, J. (2014). The Ultimate Beginner's Guide To Instagram.[Online]. Diakses dari: https://jennstrends.com/wp-content/uploads/2014/05/The-UltimateBeginners-Guide-To-

Instagram.pdf?_cf_chl_jschl_tk_=pmd_3cb572736190e8b40fc10ee5dbf7c 296be7cdad7-1628009844-0-gqNtZGzNAmKjcnBszQd6 (4 Agustus 2021).

Hermana, D., \& Barlian, U.C. (2017). Komunikasi dalam Organisasi. [Online]. 
Diakses dari: https://media.neliti.com/media/publications/77643-IDkomunikasi-dalam-organisasi.pdf (20 Juli 2021).

Hosnan, M. (2014). Pendekatan Saintifik dan Kontekstual dalam Pembelajaran Abad 21 kunci sukses implementasi kurikulum 2013. Jakarta: Ghalia Indonesia. Ibrahim, M. (2015). Pembelajaran Biologi Abad Ke-21 dalam Desain, Strategi, dan Menjawab Tantangan Pendidikan Global. Seminar Nasional Universtas Muhammadhiyah Malang. Malang: 21 Maret 2015.

KBBI. (t.t.). Kamus Besar Bahasa Indonesia (KBBI). [Online]. Diakses dari: https://kbbi.web.id/riset (1 Agustus 2021).

Kemendikbud. (2014). Peraturan Pemerintah Republik Indonesia Nomor 19 Tahun 2005 Tentang Standar Nasional Pendidikan. [Online]. Diakses dari: http://www.paudni.kemdikbud.go.id/wp-content/uploads/2014/08/PP-no19th-2005-ttg -standar-nasional-pendidikan.pdf (9 Juli 2021).

Kementerian Lingkungan Hidup. (2004). Rencana Tindak Pembangunan Berkelanjutan: Indikator Keberhasilan, Program, dan Kegiatan. Jakarta.

Koentjaraningrat. (1990). Metode-Metode Penelitian Masyarakat. Jakarta: Gramedia.

Krishnamurti, Y. (2000). Perlindungan Keanekaragaman Hayati dan Permasalahannya. Seminar Pusat Pengembangan Teknik dan Lingkungan Hidup (P2TLH).

Luczak-Roesch, M., et al. (2019). Citizen scientists in the classroom: Investigating the role of online citizen science in primary school science education. Teaching \& Learning Research Initiative.

Lukyanenko, R. (2020). A vision for the future of digital citizen science. December 2019, 0-4.

Mailhiot, A. S. (2014). DEVELOPING R ESEARCH S KILLS WITH L OW S TAKES A SSIGNMENTS. 8(1).

Manik, N.A. (2015). Hubungan Penguasaan Kosakata terhadap Kemampuan Menulis Karangan Eksposisi oleh Siswa Kelas X SMA Parulian 1 Medan Tahun Ajaran 2015/2016. [Online]. Diakses dari: http://repository.uhn.ac.id/bitstream/handle/123456789/610/Nelly\%20Agusti na\%20Manik.pdf?sequence=1 (4 Agustus 2021). 
Meerah, T. S. M., \& Arsad, N. M. (2010). Developing research skills at secondary school. Procedia - Social and Behavioral Sciences, 9, 512-516. https://doi.org/10.1016/j.sbspro.2010.12.189

Miller, J. (2014). Building Academic Literacy and Research Skills by Contributing to Wikipedia: A Case Study at an Australian University. Journal of Academic Lnguage and Learning, 8(2), A72-A86.

Nov, O., O. Arazy, \& D. Anderson. (2014). Scientists@Home: what drives the quantitiy and quality of online citizen science participation?. PLoS One. 9(4).

Paidi. (2007). Peningkatan Scientific Skill Siswa Melalui Implementasi Metode Guided Inquiry pada Pembelajaran Biologi di SMAN 1 Sleman. [Online]. Diakses dari: http://staff.uny.ac.id/20Paid/UNY.pdf (20 Juli 2021).

Pandya, R., \& Dibner, K. A. (2019). Learning through citizen science: Enhancing opportunities by design. In Learning Through Citizen Science: Enhancing Opportunities by Design. https://doi.org/10.17226/25183

Partbership Forum for $21^{\text {st }}$-Century Skills. (2008). Learning for the $21^{\text {st }}$ century: A report and mile guide for $21^{\text {st }}$ century skills. Washington: Partnership for $21^{\text {st }}$ Century Skills.

Peraturan Menteri Pendidikan dan Kebudayaan Republik Indonesia Nomor 37 Tahun 2018 tentang Kompetensi Inti dan Kompetensi Dasar Pelajaran pada Kurikulum 2013.

Prahmana, R. C. I., Kusumah, Y. S., \& Darhim, D. (2016). Keterampilan Mahasiswa dalam Melakukan Penelitian Pendidikan Matematika melalui Pembelajaran Berbasis Riset. Beta Jurnal Tadris Matematika, 9(1), 1. https://doi.org/10.20414/betajtm.v9i1.8

Primack, R. B., Supriyatna, J., Indrawan, M., \& Kramadibrata, P. (1998). Biologi Konservasi. Jakarta: Yayasan Obor Indonesia.

Rahardjo, M. (2017). Merumuskan Pertanyaan Penelitian (Bahan Kuliah Metodologi Penelitian Program S2 MPI). [Online]. Diakses dari: http://repository.uin-malang.ac.id/1124/1/merumuskan.pdf (4 Agustus 2021).

Rahayu, G. D. S., \& Setiyadi, R. (2018). Penerapan Model Project Citizen dalam Upaya Meningkatkan Kecerdasan Ekologis. Mimbar Sekolah Dasar, 5(1), 31. https://doi.org/10.17509/mimbar-sd.v5i1.9684 
Retnowato, T. (2010). Studi Keanekaragaman Vegetasi di Hutan Rakyat Kabupaten Pacitan sebagai Alternatif Sumber Belajar Biologi di SMA pada Pokok Bahasan Keanekaragaman Hayati. (Skripsi). Universitas Islam Negeri Sunan Kalijaga. Yogyakarta.

Riyanda, Aa. R., Herlina, K., \& WIcaksono, B. A. (2020). EvaluasiImplementasi Sistem Pembelajaran Daring Fakultas Keguruan dan Ilmu Pendidikan Universitas Lampung. IKRA_ITH HUMANIORA: Jurnal Sosial dan Humaniora, 4(1), 66-71.

Rusmana, Andri. (2019). Penerapan Pendekatan Science Writing Heuristic untuk Meningkatkan Keterampilan Riset dan Pengetahuan Prosedural Siswa pada Pembelajaran Biologi. (Skripsi). Universitas Pendidikan Indonesia. Bandung. Salpeter, J. (2008). $21^{\text {st }}$ Century Skills: Will our students be prepared?. [Online]. Diakses dar: http://techlearning.com/PrintableArticle.aspx?id=13832. (7 Juli 2021)

Santosa, T.A., Lufri, Razak, A., Sastria, E., \& Zulyusri. (2021). Pengaruh Penggunaan Umpan Balik (Feedback) Terhadap Hasil Belajar Siswa Dalam Mata Pelajaran Biologi. Natural Sciences: Jurnal Penelitian Bidang IPA dan Pendidikan IPA, 7(1), 22-27.

Sari, D. P. (2018). Membangun Keterampilan Riset Abad Ke-21 Siswa melalui Learning Managements System Berbasis Edmodo pada Pembelajaran Proyek Biologi. (Skripsi). Universitas Pendidikan Indonesia. Bandung.

Seago, J. J. (1992). The role of research in undergraduate instruction. The American Biology Teacher, 54(7).

Shah, H. R. \& Martinez, L. R. (2016). Current Approaches in Implementing Citizen Science in The Classroom. Journal of Microbiology \& Biology Education. 17(1).

Siswono, T. Y. E. (2010). Penelitian Pendidikan Matematika. Surabaya: Unesa University Press.

Siyoto, S. \& Sodik, A. (2015). Dasar Metodologi Penelitian. Kediri: Literasi Media Publishing.

Soendari, T. (2014). Metode Penelitian Deskriptif. [Online]. Diakses dari: http://file.upi.edu/Direktori/FIP/JUR._PEND._LUAR_BIASA/195602141980 
032-

TJUTJU_SOENDARI/Power_Point_Perkuliahan/Metode_PPKKh/Penelitian

_Deskriptif.ppt_[Compatibility_Mode].pdf (4 Agustus 2021).

Sternberg, R.J. (1988). The Psychologist'sCompanion: A Guide to Scientific Writing for Students and Researchers. Leichester: Cambridge University Press. Sugiyono. (2014). Metode Penelitian Pendidikan Pendekatan Kuantitatif, Kualitatif dan $R \& D$. Bandung: Alfabeta.

Sunarmi, S. (2014). Melestarikan Keanekaragaman Hayati melalui Pembelajaran di Luar Kelas dan Tugas yang Menantang. Jurnal Pendidikan Biologi, 6(1), 3849.

Supriyadi. (2018). Upaya Meningkatkan Keterampilan Berbasis Proyek dan Hasil Belajar IPA dengan Menerapkan Model Pembelajaran Project Based Learning (PJBL) Materi Reproduksi Tumbuhan di Kelas IX SMP Negeri 1 STABAT. Jurnal Pelita Pendidikan, 6(4).

Supriyatna, J. (2008). Melestarikan Alam Indonesia. Jakarta: Yayasan Obor Indonesia.

Sutia, C. (2018). Membangun Keterampilan Riset Abad Ke-21 Siswa melalui Learning Management System Berbasis Google Classroom pada Pembelajaran Proyek Biologi. (Skripsi). Universitas Pendidikan Indonesia. Bandung.

Suyana, N. (2017). Peningkatan Penguasaan Kosakata Siswa SMP melalui Penggunaan Media Daftar Kosakata. UTILITY: Jurnal Ilmiah Pendidikan dan Ekonomi. 1(1), 86-93.

Trilling, B. \& Fadel, C. (2009). $21^{\text {st }}$ Century Skills: Learning for Life in Our Times. San Fransisco: John Wiley \& Sons.

Trumbull, D. J., Bonney, R., Bascom, D., \& Cabral, A. (2000). Thinking scientifically during participation in a citizen-science project. Science Education, $\quad 84(2), \quad$ 265-275. https://doi.org/10.1002/(SICI)1098237X(200003)84:2<265::AID-SCE7>3.0.CO;2-5

Ullrich, Christy. (2012). Citizen Science. [Online]. Diakses dari: https://www.nationalgeographic.org/encyclopedia/citizen-science/ Agustus 2021). 
Webb, F., Smith, C., \& Worsfold, K. (2011). Griffith graduate attributes Research Skills Toolkit. [Online]. Diakses dari: htttp://www.griffith.edu.au/gihe/resources-support/graduate-attributes. (7 Juli 2021).

Wenning, C. J. (2007). Assesing Inquiry Skills as a Component of Scientific Literacy. Journal Physics Teacher Education. 4(2).

Willison, J., \& Buisman-Pijlman, F. (2016). PhD prepared: research skill development across the undergraduate years. International Journal for Researcher Development. 7(1), 63-83.

Willison, J., \& O’Regan, K. (2007). Commonly known, commonly not known, totally unknown: a framework for students becoming researchers. Higher Education Research and Development, 26(4), 393-409. https://doi.org/10.1080/07294360701658609

Zainul, A \& Nasoetion, N. (2001). Penilaiam Hasil Belajar. Jakarta: Direktorat Jendral Pendidikan Tinggi. 